\title{
GAMBARAN KUALITAS HIDUP PESERTA PROLANIS DI PUSKESMAS PETANG 1 KABUPATEN BADUNG BALI
}

\author{
Ni Luh Putu Sekardiani \\ UPT Puskesmas Petang 1 Badung, Bali \\ Email : sekardiani@gmail.com
}

\begin{abstract}
ABSTRAK
Latar Belakang: Kegiatan Prolanis di Puskesmas Petang 1 Kabupaten Badung Bali sudah rutin dilaksanakan setiap bulanya, dari 30 peserta yang terdaftar, 16 diantaranya aktif dan rutin mengikuti kegiatan tersebut, sedangkan sisanya kurang aktif. Dari rangkaian kegiatan Prolanis yang telah dilakukan petugas kesehatan di Puskesmas Petang 1 Kabupaten Badung Bali, maka perlu adanya evalusi keberhasilan dari kegiatan tersebut. Salah satu evaluasi yang dirasa perlu untuk dilakukan adalah mengenai kualitas hidup peserta Prolanis itu sendiri, sehingga dapat diketahui apakah kegiatan Prolanis yang selama ini dilaksanakan berdampak pada kualitas hidup pesertanya

Tujuan: Mengetahui gambaran gambaran kualitas hidup peserta prolanis di Puskesmas Petang 1 Kabupaten Badung Bali

Metode: Jenis penelitian ini merupakan penelitian deskriptif dengan pendekatan survey. Teknik sampel yang digunakan dalam penelitian ini adalah teknik total sampling, sampel dalam penelitian ini berjumlah 30 responden. Variabel yang diteliti adalah kualitas hidup peserta prolnis dengan menggunakan instrument WHOQoL-BREF. Analisa data menggunakan analysis deskriptif sederhana

Hasil: variabel kualiatas hidup secara umum menunjukkan kategori sedang (86.7\%), skor kualitas hidup pada dimensi fisik sebagian besar masuk kategori sedang (73.3\%). Skor kualitas hidup pada dimensi psikososial sebagian besar masuk pada kategori tinggi (66.7\%). Skor kualitas hidup pada dimensi social masuk pada kategori sedang (83.3\%) dan skor kualitas hidup pada dimensi lingkungan juga masuk pada kategori sedang (96.7\%).

Kesimpulan: Kualiatas hidup peserta prolanis di Puskesmas Petang 1 Kabupaten Badung Bali secara umum masuk kategori sedang.
\end{abstract}

Kata Kunci: Kualiatas hidup, WHOQoL-BREF, Prolanis

\section{PENDAHULUAN}

Terjadi peningkatan prevalensi hipertensi dari 7,6 persen tahun 2007 menjadi 9,5 persen tahun 2013 . Hal yang sama untuk stroke juga meningkat dari 8,3 per1000 (2007) menjadi 12,1 per1000 (2013). Demikian juga untuk Diabetes melitus yang berdasarkan wawancara juga terjadi peningkatan dari 1,1 persen (2007) menjadi 2,1 persen (2013). Peningkatan prevalensi kasus penyakit kronis pada masyarakat khususnya pada lansia di Indonesia setiap tahunnya memerlukan program khusus guna mencegah komplikasi (Kemenkes, 2013).

Pemerintah melalui Badan
Penyelenggaraan Jaminan Sosial Kesehatan (BPJS Kesehatan) telah bekerja sama dengan pihak pelayanan fasilitas kesehatan khususnya Puskesmas untuk melaksanakan suatu program yang terintegrasi dengan model pengelolaan penyakit kronis bagi penderita penyakit kronis yang disebut sebagai "PROLANIS" (Program Pengelolaan Penyakit Kronis). Prolanis merupakan pelayanan kesehatan dan pendekatan proaktif yang dilaksanakan secara terintegratif yang melibatkan peserta, fasilitas kesehatan, dan BPJS kesehatan dalam rangka pemeliharaan kesehatan bagi penderita penyakit kronis (khususnya penyakit 
N L P Sekardiani | Gambaran Kualitas Hidup Peserta Prolanis di Puskesmas Petang 1 Kabupaten Badung Bali

Hipertensi dan DM tipe 2) untuk mencapai kualitas hidup yang optimal (Idris, 2014)..

Kegiatan Prolanis ini mencangkup upaya-upaya pencegahan komplikasi berlanjut dan peningkatan kesehatan masyarakat, yaitu meliputi kegiatan konsultasi medis, klub prolanis, home-visit, dan skrinning kesehatan. Kegiatan Prolanis lebih mengutamakan kemandirian pasien dan sebagai upaya promotif serta preventif dalam penanggulangan penyakit kronis. Tujuan Prolanis mendorong peserta penyandang penyakit kronis mencapai kualitas hidup optimal dan $75 \%$ peserta memiliki hasil "baik" pada pemeriksaan spesifik terhadap penyakit DM Tipe II dan Hipertensi sehingga dapat mencegah timbulnya komplikasi penyakit (Idris, 2014).

Beberapa penelitian epidemiologi memperoleh hasil bahwa lanjut usia yang mengalami gangguan penyakit kronis cenderun mempengaruhi tingkat kualitas hidupnya (Yusup, 2010). Menurut Studi yang dilakukan Degl'Innocenti (2002), pada seseorang dengan penderita penyakit hipertensi terjadi masalah pada kualitas hidup sehingga menurunkan angka harapan hidupnya.

Kegiatan Prolanis di Puskesmas Petang 1 Kabupaten Badung Bali sudah rutin dilaksanakan setiap bulanya, dari 30 peserta yang terdaftar, 16 diantaranya aktif dan rutin mengikuti kegiatan tersebut, sedangkan sisanya kurang aktif. Kegiatan Prolanis yang dilakukan di Puskesmas Petang 1 Kabupaten Badung Bali diantaranya adalah pemeriksaan kesehatan, pemantauan dan pengendalian gula darah dan tekanan darah, konsultasi kesehatan serta kegiatan senam rutin.
Dari rangkaian kegiatan Prolanis yang telah dilakukan petugas kesehatan di Puskesmas Petang 1 Kabupaten Badung Bali, maka perlu adanya evalusi keberhasilan dari kegiatan tersebut. Salah satu evaluasi yang dirasa perlu untuk dilakukan adalah mengenai kualitas hidup peserta Prolanis itu sendiri, sehingga dapat diketahui apakah kegiatan Prolanis yang selama ini dilaksanakan berdampak pada kualitas hidup pesertanya.

\section{METODE}

Penelitian ini merupakan penelitian deskriptif menggunakan pendekatan survey (Notoatmodjo, S. 2010). Populasi dalam penelitian ini adalah seluruh peserta terdaftar Prolanis di wilayah kerja Puskesmas Petang 1 Kabupaten Badung Bali yang berjumlah 30 peserta, dengan teknik pengambilan sampel dilakukan secara total sampling (Arikunto, 2006).

Variabel yang diukur dalam penelitian ini adalah kualitas hidup, yang diukur dengan menggunakan kuesioner kualitas hidup menurut WHOQoL-BREF (Skivington, 2004). Terdapat 26 pertanyaan dalam kuesioner tersebut yang terdiri dari pertanyaan kualitas hidup secara umum, dimensi kesehatan fisik, psikologis, social dan lingkungan. Total nilai kualiatas hidup berkisar 26-130 yang terbagi menjadi 3 (tiga) kategori yaitu kualitas hidup rendah (skor 26-61), kualitas hidup sedang (skor 62-96) dan kualitas hidup tinggi (skor 97-130). Data yang diperoleh dianalisis menggunakan analisis deskriptif sederhana (Arikunto, 2011). 
N L P Sekardiani | Gambaran Kualitas Hidup Peserta Prolanis di Puskesmas Petang 1 Kabupaten Badung Bali

HASIL

Sebagian besar responden berusia antara 60-70 tahun (70\%) dan mayoritas berjenis kelamin perempuan (66.7\%). Pada karakteristik pendidikan sebagian besar SD (53.3\%). Profil pengendalian kadar gula darah dan tekanan darah pada responden sebagian besar kurang terkontrol (Tabel 1). Pada pengukuran variabel kualiatas hidup secara umum menunjukkan kategori sedang Tabel 1. Karakteristik Responden $(n=30)$

\begin{tabular}{lcc}
\hline Karakteristik & Frekuensi & Persentase \\
\hline Usia (Tahun) & 9 & $30 \%$ \\
$\quad \geq 50-59$ & 21 & $70 \%$ \\
$60-70$ & 0 & $0.0 \%$ \\
$\quad>70$ & 10 & $33.3 \%$ \\
Jenis kelamin & & \\
$\quad$ Laki-laki & 20 & $66.7 \%$ \\
$\quad$ Perempuan & & $53.3 \%$ \\
Pendidikan & 16 & $30 \%$ \\
$\quad$ SD & 9 & $16.7 \%$ \\
SMP & 5 & $40 \%$ \\
SMA/SMK & & $60 \%$ \\
Profil Pengendalian Gula Darah & 12 & $33.3 \%$ \\
$\quad$ Terkontrol & 18 & $66.7 \%$ \\
$\quad$ Kurang terkontrol & & \\
Profil Pengendalian Tekanan Darah & 10 & \\
$\quad$ Terkontrol & 20 & \\
$\quad$ Kurang terkontrol & & \\
\hline
\end{tabular}

Tabel 2. Gambaran Kualitas Hidup Peserta Prolanis di Puskesmas Petang 1 Kabupaten Badung Bali $(n=30)$.

\begin{tabular}{lcc}
\hline Kualitas Hidup & Frekuensi & Persentase \\
\hline Kualitas Hidup Secara Umum & & \\
Tinggi & 4 & $13.3 \%$ \\
Sedang & 26 & $86.7 \%$ \\
Rendah & 0 & $0.0 \%$ \\
Dimensi Fisik & & \\
$\quad$ Tinggi & 8 & $26.7 \%$ \\
Sedang & 22 & $73.3 \%$ \\
Rendah & 0 & $0.0 \%$ \\
Dimensi Psikologis & 20 & $66.7 \%$ \\
$\quad$ Tinggi & 10 & $33.3 \%$ \\
Sedang & 0 & $0.0 \%$ \\
Rendah & & $10.0 \%$ \\
Dimensi Sosial & 3 & $83.3 \%$ \\
Tinggi & 25 & $6.7 \%$ \\
Sedang & 2 & $3.3 \%$ \\
Rendah & 1 & $96.7 \%$ \\
Dimensi Lingkungan & $10 \%$ \\
Tinggi & 29 & $0.0 \%$ \\
Sedang & 0 & \\
Rendah & &
\end{tabular}


N L P Sekardiani | Gambaran Kualitas Hidup Peserta Prolanis di Puskesmas Petang 1 Kabupaten Badung Bali

\section{PEMBAHASAN}

Hasil penelitian menunjukan sebagian besar baik gula darah maupun tekanan darah responden kurang terkontrol dengan baik. Responden yang masuk dalam kategori terkontrol mengatakan menjaga kadar gula darah dan tekanan darahnya agar selalu stabil dimulai dari adanya kesadaran diri sendiri untuk mempertahankan kesehatannya, sehingga termotivasi untuk mematuhi jadwal dan menu makanan yang disarankan oleh dokter pada saat kegiatan prolanis berlangsung. Sedangkan responden yang kurang terkontrol mengatakan tidak mematuhi jadwal dan menu makanan yang disarankan dokter disebabkan karena bosan dengan menu makanan yang dianjurkan.

Masih banyaknya peserta prolanis yang kurang terkontrol kadar gula darah dan tekanan darahnya tentunya menjadi evaluasi bagi petugas kesehatan khususnya bagi penanggungjawab kegiatan prolanis di Puskesmas Petang 1 Kabupaten Badung Bali untuk meningkatkan pengetahuan para peserta prolanis dalam hal kepatuhan dalam mengendalikan kadar gula darah dan tekanan darahnya. Salah satu cara dengan giat melakukan penyuluhan secara mendalam kepada peserta. Penelitian yang dilakukan Prastiwi (2007) menemukan bahwa kepatuhan dalam mengontrol kesehatan menjadi meningkat setelah dilakukan edukasi atau penyuluhan.

Perawat harus meningkatkan perannya sebagai edukator yaitu dengan memberikan penyuluhan mengenai diabetes mellitus dan hipertensi. Perawat juga harus memberikan motivasi kepada pasien agar mau mengontrol penyakitnya. Khusunya bagi perawat komunitas untuk lebih meningkatkan perannya baik itu sebagai edukator, motivator, fasilitator maupun dalam memberikan asuhan keperawatan (Misdarina, 2012).

Pada variabel kualitas hidup, sebagian besar pasien Prolanis di Puskesmas Petang 1 Kabupaten Badung Bali kualiatas hidup secara umum menunjukkan kategori sedang (86.7\%), sedangkan sisanya masuk kategori tinggi (13.3\%). Hasil penelitian kualitas hidup pada dimensi fisik, psikologis, social dan lingkungan juga menunjukkan sebagian besar masuk pada kategori sedang. Kualitas hidup responden yang sebagian besar pada kategori sedang dapat disebabkan karena penilaian responden yang kurang atau tidak puas dengan kesehatan yang dirasakannya saat ini dan tak banyak responden yang beranggapan bahwa penyakitnya sangat sulit untuk disembuhkan, terutama yang sudah berlangsung lama.

Petugas kesehatan di Puskesmas Petang 1 Kabupaten Badung Bali, juga harus dapat meningkatkan kepatuhan peserta prolanis. Hal tersebut dikarenakan dari 30 peserta yang terdaftar hanya 16 peserta (53.3\%) yang aktif dalam mengikuti kegiatan prolanis. Hal tersebutlah yang mungkin dialami pada peserta prolanis di Puskesmas Petang 1 Kabupaten Badung Bali sehingga menjadikan pengontrolan kadar gula darah dan tekanan darah para peserta tidak terkontrol dengan baik yang berdampak pada kualitas hidup secara keseluruhan yang masuk kategori sedang

Kepatuhan peserta prolanis sangat penting untuk meningkatkan kualitas hipup pasien tersebut. Penelitian yang dilakukan oleh Hastuti (2017), ada hubungan antara 
N L P Sekardiani | Gambaran Kualitas Hidup Peserta Prolanis di Puskesmas Petang 1 Kabupaten Badung Bali

keaktifan peserta program pengelolaan penyakit kronis (Prolanis) terhadap kualitas hidup di Puskesmas Serayu Larangan ( $p$ value $=0,009)$.

Selain peningkatan edukasi kepada peserta, petugas kesehatan di Puskesmas Petang 1 Kabupaten Badung Bali perlu untuk melakukan pendekatan kepada keluarga peserta prolanis guna menumbuhkan kepatuhan dalam menjalani kegitan tersebut. Penelitian yang dilakukan Oktowaty (2018) menunjukkan ada hubungan fungsi keluarga dengan kualitas hidup pasien penyakit kronis degeneratif yang termasuk dalam kelompok Prolanis.

\section{KESIMPULAN DAN SARAN}

Hasil penelitian menunjukkan pengendalian kadar gula darah dan tekanan darah peserta prolanis di Puskesmas Petang 1 Kabupaten Badung Bali secara umum masuk kategori kurang terkontrol. Kualiatas hidup peserta prolanis di Puskesmas Petang 1 Kabupaten Badung Bali secara umum masuk kategori sedang. Perlu adanya peningatan pelayanan pada kegiatan prolanis di 1 Kabupaten Badung Bali, khususnya dalam bidang edukasi kepada peserta dan peningkatan kepatuhan peserta dalam menjalani kegiatan prolanis tersebut.

\section{DAFTAR PUSTAKA}

Arikunto, S (2011). Teknik Analisis Data. Jakarta : PT. Gramedia.

Arikunto, S. (2006). Prosedur Penelitian Suatu Pendekatan Praktik EdisiRevisi. Jakarta: Rineka Cipta

Degl'Innocenti A., Elmfeldt D., Hansson L., Breteler M., James O., Lithell $H_{\text {., }}$ Olofsson B., Skoog I., Trenkwalder P., Zanchetti A., Wiklund I. (2002). Cognitive function and health-related quality of life in elderly patients with hypertension--baseline data from the study on cognition and prognosis in the elderly (SCOPE). Blood Press. 11(3):157-65.

Hastuti, U.T. (2017). Hubungan Keaktifan Dalam Program Pengelolaan Penyakit Kronis (PROLANIS) Dengan Kualitas Hidup Peserta di Puskesmas Serayu Larangan Purbalingga. (Skripsi). Sekolah Tinggi IImu Kesehatan Harapan Bangsa Purwokerto

Idris, F. (2014). Panduan Praktis PROLANIS (Program PengelolaanPenyakit Kronis). Jakarta: BPJS Kesehatan

Kemenkes RI. (2013). Riset Kesehatan Dasar; RISKESDAS. Jakarta: Balitbang Kemenkes RI

Misdarina \& Apriani Y. (2012). Pengetahuan diabetes melitus dengan kadar gula darah pada pasien DM tipe 2. Jurnal Keperawatan Klinis, 2(1):1-5.

Notoatmodjo, S. (2010). Metodologi Penelitian Kesehatan. Jakarta: Rineka Cipta.

Oktowaty S., Setiawati E.P., Arisanti N. (2018). Hubungan Fungsi Keluarga Dengan Kualitas Hidup Pasien Penyakit Kronis Degeneratif di Fasilitas Kesehatan Tingkat Pertama. JSK, $4(1): 1-6$

Pratiwi, LS. (2007). Hubungan antara tingkat pengetahuan tentang diet diabetes mellitus dengan kepatuhan dalam pelaksanaan diet pada pasien DM di poli diabetes RSUD Margono Soekarjo (Skripsi). Poltekkes Semarang

Skivington, L.C. (2004). The World Health Organisation's WHOQOL-BREF Quality Of Life. Netherlands: Kluwer publisher

Yusup, L. (2010). Rahasia Tetap Muda Hingga Lansia. Jakarta : Gramedia Pustaka 